\title{
Comparison Between Atmospheric Turbidity Coefficients of Desert and Temperate Climates
}

\begin{abstract}
Hamdy K. Elminir, U. A. Rahuma, V. Benda
Knowledge of the solar radiation available on the earth's surface is essential for the development of solar energy devices and for estimating of their performance efficiencies. For this purpose it is helpful to study the attenuation of direct normal irradiance by the atmosphere, in terms of fundamental quantities, including optical thickness, relative optical air mass, water vapor content, and aerosol amount. In the present article, we will not deal with cloudy atmospheres because of their great variability in space and time, but will focus our attention on atmospheres characterized by the complete absence of condensed water.

The objectives of this article are to report data on aerosol optical depth and atmospheric turbidity coefficients for a desert climate, and to compare them with those of a temperate climate. Aerosol optical depth, the Linke turbidity factor, $T_{L}$, and ngström turbidity coefficients, $\beta$, are calculated from measurements of broadband filters at Helwan, Egypt, which has a desert climate. A linear regression model is to be determined between the Linke factor and the ngström turbidity coefficient. This relation is compared with similar relations reported for a temperate climate [Prague, Czech Republic]. This comparison is made to determine whether a universal relation exists between these two important coefficients, or whether the relation is location dependent.
\end{abstract}

Keywords: energy demand, environmental management, industrial wastes, sulfur dioxide, carbon dioxide, aerosol optical depth, Linke turbidity factor, ngström turbidity coefficient.

\section{Introduction}

The increase in terrestrial applications of solar radiant energy has given impetus to the study of solar energy availability in many areas of the world. When passing through the earth's atmosphere, extraterrestrial solar radiation is subjected to attenuation due to scattering by the air molecules and aerosols, and due to absorption by various atmospheric components, mainly ozone, water vapor, oxygen and carbon dioxide. The extinction of the radiation is strongly dependent on the state of the sky, whether cloudy or not, the cleanliness of the atmosphere, and the amount of gaseous absorbers. Theoretical analysis of the attenuation of solar radiation passing through clouds requires a great deal of information regarding instantaneous thickness, position and number of layers of clouds, as well as their optical properties. However, for technological utilization of solar energy, a study of solar radiation under cloudless skies is very important, particularly for solar systems using concentrators. The attenuation of radiation through a real atmosphere versus that through a clean dry atmosphere gives an indication of the atmospheric turbidity. Several atmospheric turbidity coefficients have been introduced during the past decades in order to quantify the influence of atmospheric aerosol content on direct radiation received at the earth's surface. The most currently used are the Linke turbidity factor, $T_{\mathrm{L}},[1]$ and the ngström turbidity coefficient, $\beta$, [2]. Linke's turbidity factor refers to the whole spectrum, i.e., overall spectrally integrated attenuation, which includes presence of gaseous, water vapor and aerosols, and indicates the number of ideal (clean and dry) atmospheres that produce the same extinction of the extraterrestrial solar beam as the real atmosphere. On the other hand the ngström turbidity coefficient is obtained from spectral measurements and is an indication only of the amount of aerosols in the atmosphere.

In the present work the Helwan site was used as sampling station for collecting atmospheric aerosol samples over sev- eral years. The examined concentrations were compared with other data representative of source areas influencing the Helwan atmosphere. A substantial part of the anthropogenic emissions of primary particles in Helwan are fly ash particles from solid fuel combustion and inorganic particles from iron and steel production, cement production and a variety of industrial processes. The question of the existence and tracer power of regional elemental characteristics reflecting the structure of emission sources at a given location has been treated in a number of publications. As summarized in some reference papers $[3,4,5]$, single element tracers or ratios of elemental concentrations can be used for studying the nature of major emission sources in the region as well as for pinpointing the source areas of aerosols transported to the site of observation.

Rizk H. F., et al. [6], studied the effect of pollutant aerosols on spectral atmospheric transmissivity in Cairo, using a Volz sun photometer in the period July 1981-June 1982 . They found that the annual loss in solar energy absorption, in the case of dust-free atmosphere in Cairo, due to pollutant aerosols for each of the blue, green and red bands were $37 \%$, $21 \%$, and $19 \%$, respectively. Also, radiation loss due to pollutant aerosols is strongly wavelength dependent, where shorter wavelengths are much more seriously affected than longer wavelengths. Fathy A. M., [7] found that the turbidity factor had reached three times the value that was found before industries came to Helwan. The pollution reduced the integrated ultraviolet direct solar radiation by $50 \%$ due to cement exhaust in the atmosphere. Rahoma U. A., [8] revealed a decrease of direct solar radiation by $30-45 \%$ in comparison with the results of $1922-1927$, and by $20 \%$ in comparison with 1967 . Moreover, the intensity of direct solar radiation was about $50 \%$ lower than the extraterrestrial solar radiation.

At the Prague site, which is not particularly influenced by local industrial processes, the primary inorganic aerosol particles may not account for more than a few percent (5-10\%) 
of the total particle mass. Moreover, due to more efficient emission controls, the concentrations of calcium and other inorganic primary particle components have been decreasing substantially over the last decades $[9,10]$. In this work we document the general tendency of atmospheric turbidity by means of the variations at selected wavelengths of the aerosol optical depth and its spectral characteristics during the measured period, together with a short statistical analysis. All this analysis gives a good representation of the aerosol turbidity characteristics in our study areas. In section 2 we briefly review the experimental measurements, and the procedures are revised in section 3. A summary of factors affecting atmospheric turbidity is given in section 4 , and the results are discussed in section 5 .

\section{Apparatus and measurements}

Measuring apparatus was installed on the terrace of the research laboratory at the National Research Institute of Astronomy and Geophysics in Helwan, Egypt (latitude 29 52' N and longitude $31^{\circ} 20^{\prime} \mathrm{E}$ ), where it is located on hilltop site about $30 \mathrm{~km}$ south of Cairo in desert surroundings. In this study, the broadband filter method was used to measure quantities of normal radiation at different bands. The filters used in this study are Schott filters (2 mm thick), whose cutoff wavelengths were determined using a spectrophotometer. These filters were arranged on a rotatable disk and mounted on an Eppley normal incidence pyrheliometer. Their main characteristics (interval bands, $\mu \mathrm{m}$ and reduction factor) are given in Table 1.

Total solar radiation intensity was monitored with a high precision pyranometer, which is sensitive in the wavelength range from 300 to $3000 \mathrm{~nm}$. Sky diffuse radiation was measured by a pyranometer equipped with a special shading device to exclude direct radiation from the sun. Due to the lack of measured tilted surface solar radiation data, models were employed to estimate the radiation incident on a tilted surface from measured horizontal radiation. The results of these calculations are tabulated and plotted against the angle of tilt for summer, winter and all-year-round intended use.

Table 1: Filter characteristics

\begin{tabular}{|l|c|c|c|}
\hline Old name & $\begin{array}{c}\text { Filter } \\
\text { Reference }\end{array}$ & $\begin{array}{c}\text { Interval Bands } \\
{[\mu \mathrm{m}]}\end{array}$ & $\begin{array}{c}\text { Filter Factor, } \\
f\end{array}$ \\
\hline OG1 & OG530 & $0.530-0.630$ & 1.082 \\
RG2 & RG630 & $0.630-0.695$ & 1.068 \\
RG8 & RG695 & $0.695-2.900$ & 1.042 \\
Clear & - & $0.250-2.800$ & 1.080 \\
\hline
\end{tabular}

Meteorological instrumentation was used to provide the necessary information about the weather. This data was used to determine the stability class of the atmosphere, from which the rate of dust deposition was calculated [11].

The concentration of dust in the atmosphere was monitored by means of a portable air sampler. The physical design of this sampler is based on aerodynamic principles, which result in the collection of particles of 100 microns (Stokes equivalent diameter) and less. To measure the concentration, air was drawn into the sampler, and, by virtue of their inertia, the particles were deposited on membrane filters. The filters were weighed before and after sampling to determine the mass collected. The weight was divided by the surface area from which they were collected to give the dust deposition density in $\mu \mathrm{g} / \mathrm{m}^{2}$. The Proton induced X-ray emission analytical method was applied to deduce the multielemental absolute concentration data on the elemental constituents of the samples.

\subsection{Database preparation}

A routine quality control procedure described in [12] has been implemented for data from the Helwan station since its inception. A daily validation test was instituted to eliminate certain days from further consideration. Days that were mostly overcast were rejected primarily because little beam radiation occurs on such days and, secondarily, because it is difficult to verify pyrheliometer data on such days. For this daily screening, only periods with solar altitudes greater than $6^{\circ}$ were considered in order to avoid the consequent refraction effects on tracking accuracy. Next, hourly databases were subjected to three types of data checks to identify missing data, data that clearly violate physical limits, and extreme data. Hours when the data were known to be "bad" or "missing" were omitted. Then, any hour with an observation that violated a physical limit or conservation principle was eliminated from the data set, including: reported hours with a diffuse fraction greater than 1 , or beam radiation exceeding the extraterrestrial beam radiation. The final data set was constructed from the measured data that passed all of the quality control checks.

\section{Mathematical formulations}

The amount of aerosols present in the atmosphere in the vertical direction is represented in terms of the number of particles per cubic meter or their mass in micrograms per cubic meter. However, it is more usual to represent the amount of aerosols by an index of turbidity. Two popular indices of turbidity are the Linke turbidity factor, $T_{\mathrm{L}}$, and the ngström turbidity coefficient, $\beta$. Both of these are used to quantify the influence of atmospheric aerosols on direct solar radiation on the earth's surface. In the following sections we present the mathematical approaches to evaluate $T_{\mathrm{L}}$ and $\beta$.

\subsection{The linke approach}

Linke's turbidity factor, $T_{\mathrm{L}}$ is an index of the number of clear dry atmospheres that would be necessary to produce the attenuation of the extraterrestrial radiation that is produced by the real atmosphere. The direct normal irradiance over the whole solar spectrum at the earth's surface is expressed in terms of $T_{\mathrm{L}}$ by:

$$
I_{\mathrm{N}}=E_{\mathrm{o}} I_{\mathrm{SC}} \exp \left(-\delta_{\mathrm{R}} T_{\mathrm{L}} m_{\mathrm{A}}\right)
$$

in which $I_{\mathrm{SC}}$ is the solar constant corrected by the eccentricity factor, $E_{\mathrm{o}}$ due to the variation in the sun-earth distance; $\delta_{\mathrm{R}}$ is the spectrally integrated optical thickness of the clean dry atmosphere; and $m_{\mathrm{A}}$ is the relative optical air mass, $m_{\mathrm{A}}$ depends on the zenith angle $\theta_{\mathrm{Z}}$, on the actual pressure, $p$, at the site, and consequently on the latitude. The following equation has been used for expressing the relative optical mass in this work:

$$
m_{\mathrm{A}}=\left(\frac{p}{1013.25}\right) \frac{1}{\cos \theta_{\mathrm{Z}}+0.15\left(93.885-\theta_{\mathrm{Z}}\right)^{-1.253}} .
$$

It can be seen from Equation 1 that the smallest value of $T_{\mathrm{L}}$ is 1 , obtained when the atmosphere is fully clean and dry. The 
optical thickness of such an atmosphere is then equal to $\delta_{R}$, which accounts for the attenuation due to the scattering by air molecules (Rayleigh scattering), absorption by ozone and by other gaseous absorbers. According to Equation 1, Linke's turbidity factor can be derived from pyrheliometric measurements of the direct normal irradiance at ground level, $I_{\mathrm{N}}$, as:

$$
T_{\mathrm{L}}=\frac{1}{\delta_{\mathrm{R}} m_{\mathrm{A}}} \ln \left(\frac{E_{\mathrm{O}} I_{\mathrm{SC}}}{I_{\mathrm{N}}}\right) .
$$

The evaluation of $T_{\mathrm{L}}$ from $I_{\mathrm{N}}$ requires the knowledge of $\delta_{\mathrm{R}}$. The values of $\delta_{\mathrm{R}}$ originally by Feussner and Dubois, [13] were presented by:

$$
\delta_{\mathrm{R}}=\left(9.4+0.9 m_{\mathrm{A}}\right)^{-1}
$$

has generally been used for calculating Linke's turbidity factor in most recent work. In 1986, a determination of $\delta_{\mathrm{R}}$ based on more accurate values of spectral extraterrestrial solar irradiance and extinction coefficients of the various attenuators was carried out by Louche, [14], who proposed the following algorithm to evaluate the optical thickness of the clean dry atmosphere from the relative air mass:

$$
\delta_{\mathrm{R}}=\frac{1}{6.5567+1.7513 m_{\mathrm{A}}-0.1202 m_{\mathrm{A}}^{2}+0.0065 m_{\mathrm{A}}^{3}-0.00013 m_{\mathrm{A}}^{4}}(5
$$

The values of $\delta_{\mathrm{R}}$ obtained by using Equation 5 are clearly different from those obtained from Kasten's Formula 4, and lead to $T_{\mathrm{L}}$ values that are also quite different. In Fig. 1 the optical thickness of the clean dry atmosphere obtained from Equations 4 and 5 is plotted.

It is evident from this diagram that the older value of $\delta_{\mathrm{R}}$ represented by Kasten's formula, Equation 4, are lower than those obtained from Equation 5. These differences are larger when $m_{\mathrm{A}}<5$ compared to when $m_{\mathrm{A}}>5$.

\subsection{The ngström approach}

The ngström turbidity coefficient is a dimensionless index that represents the amount of aerosols. It appears in an

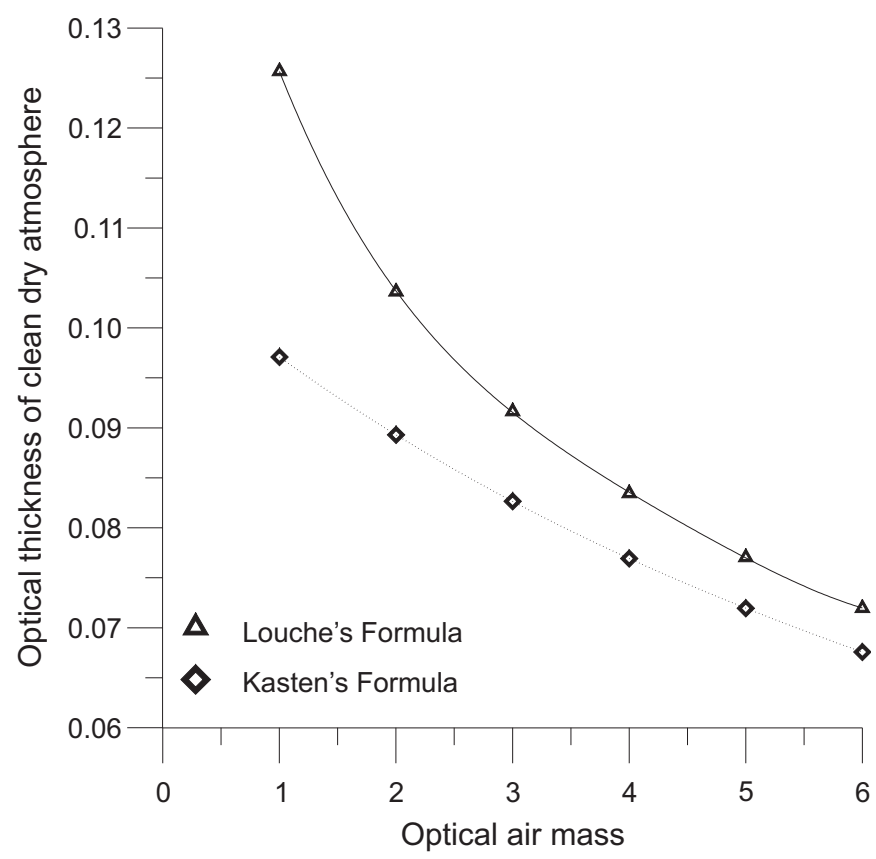

Fig. 1: Optical thickness of clean, dry atmosphere computed by various authors equation called the ngström formula, aimed at determining the spectral optical thickness relative to aerosol scattering $\delta_{\mathrm{a} \lambda}$ :

$$
\delta_{\mathrm{a} \lambda}=\beta \lambda^{-\alpha}
$$

in which $\lambda$ is the wavelength (expressed in micrometers); and $\alpha$ is the wavelength exponent, which is representative of the aerosol size distribution. It is considered that $\alpha=1.3 \pm 0.2$ is a reasonable average value [15], although ngström had shown that in a polluted atmosphere, for instance after volcanic outbreaks or forest fires, $\alpha$ may be as low as 0.5 or less. The experimental determination of ngström's turbidity coefficient $\beta$ requires measurements of the spectral direct normal irradiance at wavelengths, e.g., $0.530 \mu \mathrm{m}$ and $0.630 \mu \mathrm{m}$, in a part of the solar spectrum where absorption is negligible. ngström's turbidity coefficient can vary from 0.0 for absolutely clean atmosphere to about 0.5 for very high aerosol amounts.

The total amount of water vapor in the atmosphere in the vertical direction is highly variable and depends on the instantaneous local conditions. However, this amount, generally expressed as precipitable water thickness $W$, can be readily computed through a number of standard routine atmospherically observations, such as relative humidity $\phi_{\mathrm{r}}$, ambient temperature $T$ or vapor pressure. The precipitable water vapor thickness can vary from 0.0 to $5 \mathrm{~cm}$. Iqbal, [16] has summarized some of the most commonly used methods of computing the precipitable water vapor thickness. In this study, Leckner's formula is used to obtain $W$;

$$
W=0.493 \frac{\phi_{\mathrm{r}}}{T} \exp \left(26.23-\frac{5416}{T}\right) .
$$

\section{Site and climate dependence of solar energy collection}

\subsection{Helwan site details}

A very common weather condition in Helwan is characterized by great sunshine (>3000 hours per year), calm or light air, increased humidity during the cold season. The daily average temperature in Helwan ranges between $35.2{ }^{\circ} \mathrm{C}$ in July and $13.1^{\circ} \mathrm{C}$ in January. The relative humidity fluctuates between $39 \%$ in June and $56 \%$ in December, with visibility of about $5 \mathrm{~km}$. This restricted visibility is the result of the presence of solid particles in the atmosphere, some of which act as condensation nuclei. During such weather conditions, the reduction of solar radiation is sometimes due to the increased quantity of water vapor, sometimes to the presence of increased quantities of aerosol particles, and sometimes to the presence of both these influences. Table 2 and Fig. 2 show the annual variation of the mean monthly solar radiation and climatological data for Helwan, respectively.

Over the last 40 years, air pollution has become a serious problem in Helwan. Air quality has decreased rapidly as a result of industrialization and an increase in the number of motor vehicles. The great number of automobiles traveling on the town's narrow roads has resulted in a significant loading of the atmosphere with both solid and gaseous pollutants. A brownish cloud of air pollution forms over Helwan; it can be seen by the naked eye. This cloud denotes a high level both of $\mathrm{NO}_{2}$ pollutant and of man-made aerosols. High concentrations of particulate matter are found in Helwan, emanating 
Table 2: Annual variations in solar radiation data for Helwan

\begin{tabular}{|c|c|c|c|c|c|c|}
\hline Month & $\frac{\mathbf{G}^{2}}{\left[\mathrm{kWh} / \mathrm{m}^{2} / \text { day }\right]}$ & $\frac{\left.\mathbf{D}^{2} \text { day }\right]}{\left[\mathrm{kWh} / \mathrm{m}^{2} / \text { day }\right.}$ & $\frac{\mathbf{I}}{\left[\mathrm{kWh} / \mathrm{m}^{2} / \text { day }\right]}$ & $\begin{array}{c}\mathbf{F}_{\mathbf{1}_{2}} \\
{\left[\mathrm{kWh} / \mathrm{m}^{2} / \text { day }\right]}\end{array}$ & $\begin{array}{c}\mathbf{F}_{\mathbf{2}_{2}} \\
{\left[\mathrm{kWh} / \mathrm{m}^{2} / \text { day }\right]}\end{array}$ & $\begin{array}{c}\mathbf{F}_{\mathbf{3}_{2}} \\
{\left[\mathrm{kWh} / \mathrm{m}^{2} / \text { day }\right]}\end{array}$ \\
\hline January & 3.09 & 0.97 & 4.67 & 4.2 & 5.0 & 5.2 \\
\hline February & 3.4 & 1.21 & 4.25 & 4.8 & 5.9 & 6.0 \\
\hline March & 3.68 & 1.69 & 3.32 & 5.4 & 6.7 & 6.7 \\
\hline April & 5.11 & 1.96 & 4.47 & 5.5 & 7.0 & 7.1 \\
\hline May & 5.25 & 2.5 & 3.78 & 5.5 & 7.1 & 7.4 \\
\hline June & 5.81 & 2.69 & 4.09 & 5.9 & 8.0 & 8.5 \\
\hline July & 6.2 & 2.18 & 5.29 & 6.2 & 8.4 & 8.9 \\
\hline August & 6.46 & 1.86 & 6.63 & 6.3 & 8.3 & 8.5 \\
\hline September & 5.64 & 1.47 & 6.44 & 5.8 & 7.3 & 7.4 \\
\hline October & 4.35 & 1.11 & 5.8 & 5.4 & 6.8 & 6.9 \\
\hline November & 3.65 & 0.91 & 5.79 & 4.6 & 5.5 & 5.7 \\
\hline December & 2.78 & 0.87 & 4.47 & 4.0 & 4.8 & 5.1 \\
\hline Average & 4.62 & 1.62 & 4.92 & 5.3 & 6.73 & 6.95 \\
\hline
\end{tabular}

where the monthly means in Table 2 are:

G Global solar radiation on a horizontal surface in $\mathrm{kWh} / \mathrm{m}^{2} /$ day,

D Diffuse solar radiation in $\mathrm{kWh} / \mathrm{m}^{2} /$ day,

I Direct normal incidence of solar radiation in $\mathrm{kWh} / \mathrm{m}^{2} /$ day,

$\mathrm{F}_{1} \quad$ Solar radiation for a flat plate-facing south tilted by the latitude angle of the site in $\mathrm{kWh} / \mathrm{m}^{2} / \mathrm{day}$,

$\mathrm{F}_{2} \quad$ Solar radiation for 1-axis tracking flat plate with a north-south axis, $\mathrm{kWh} / \mathrm{m}^{2} /$ day,

$\mathrm{F}_{3} \quad$ Solar radiation for 2-axis tracking flat plate, $\mathrm{kWh} / \mathrm{m}^{2} /$ day.

from natural sources such as desert dust and from industries such as cement plants. The local industry includes four factories located from the north in Tura to the south in El-Tebeen, engineering industries (an automobile factory, a pipe and tube factory) and an iron and steel works. The prevailing wind direction is from the $\mathrm{N}$ and NE, which represents about $50 \%$ of the total direction. This leads to an important result, that is, the Tura and Helwan cement factories contribute $50 \%$ to the pollution of the Helwan site. Fig. 3 demonstrates this fact and

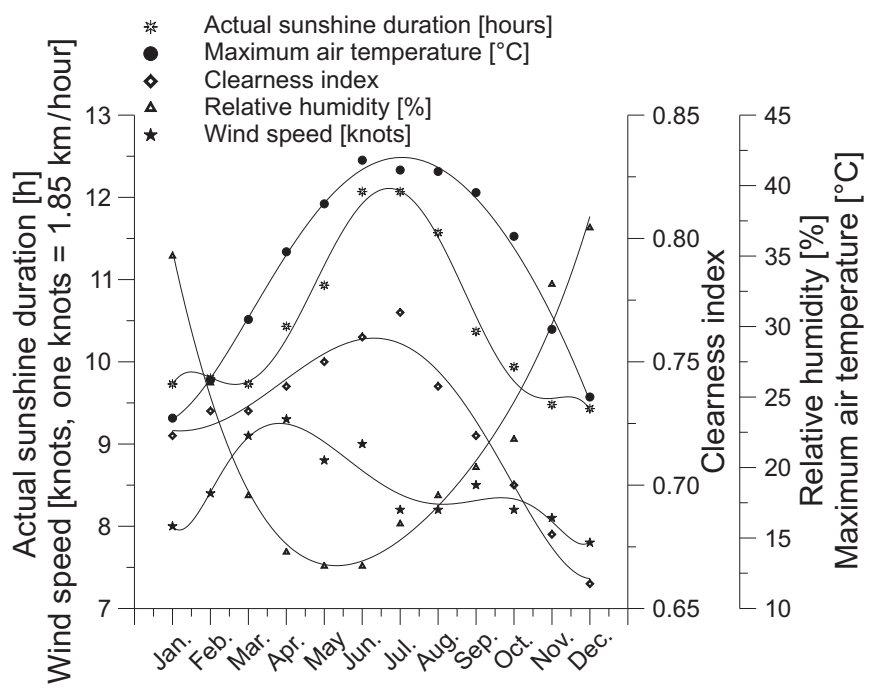

Fig. 2: Annual variations in climatological data for Helwan shows the close match between pure cement and dust settling onto the surface of the flat plate at the Helwan station.

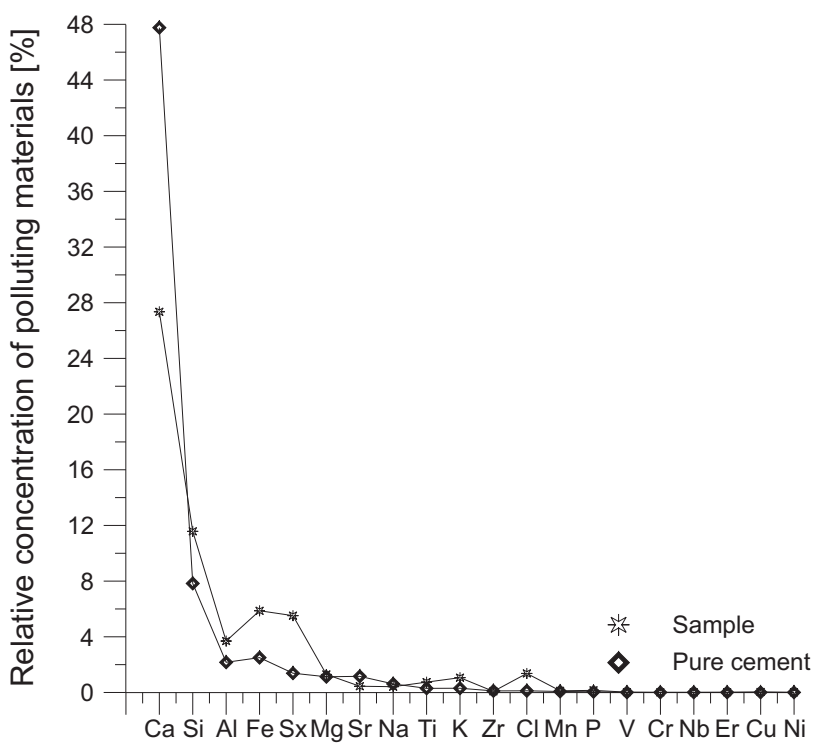

Fig. 3: Comparison between dust depositions on the flat plate and pure cement

Dust fallout is a rather informative and well-recognized indicator of air pollution. It is measured by a routine deposition method, where a calibrated vessel is placed outdoors for one month to collect dust, and the collected sample is assessed gravimetrically. It should be noted that, according the Environmental Protection Agency (EPA) regulations, the primary air standard is limited to less than $7 \mathrm{mg} / \mathrm{m}^{2} \cdot \mathrm{month}$. 
Table 3: Classification of world standard for dust fallout

\begin{tabular}{|l|c|}
\hline \multicolumn{1}{|c|}{ Degree of Pollution } & Dust full $\left[\mathrm{mg} / \mathrm{m}^{2} \cdot \mathrm{month}\right]$ \\
\hline Light & $<7$ \\
\hline Medium & $7-14$ \\
\hline High & $4-35$ \\
\hline Very high & $>35$ \\
\hline
\end{tabular}

Table 4: Annual variation of monthly dust fallout $\left(\mathrm{mg} / \mathrm{m}^{2} \cdot \mathrm{month}\right)$ on selected sites in Helwan

\begin{tabular}{|c|c|c|c|c|}
\hline Month & National Cement Co. & Portland Cement Co. & Tura Cement Co. & Helwan Observatory \\
\hline January & 252 & 103 & 327 & 21 \\
\hline February & 215 & 307 & 311 & 43 \\
\hline March & 183 & 236 & 422 & 31 \\
\hline April & 147 & 94 & 204 & 55 \\
\hline May & 320 & 112 & 1222 & 94 \\
\hline June & 138 & 38 & 243 & 13 \\
\hline July & 68 & 47 & 236 & 23 \\
\hline August & 75 & 82 & 116 & 25 \\
\hline September & 42 & 48 & 178 & 36 \\
\hline October & 47 & 50.7 & 269 & 12 \\
\hline November & 50 & 40 & 189 & 19 \\
\hline December & 53 & 50 & 287 & 26 \\
\hline Average & 132.5 & 100.64 & 333.67 & 33.17 \\
\hline
\end{tabular}

Table 5: Climatological data for Prague [Lat. 50 $04^{\prime}$, Long. $14^{\circ} 25^{\prime}$ ]

\begin{tabular}{|c|c|c|c|c|c|c|c|c|c|c|c|c|}
\hline & Jan. & Feb. & Mar. & Apr. & May & Jun. & Jul. & Aug. & Sep. & Oct. & Nov. & Dec. \\
\hline$T$ & 0.30 & 4.50 & 5.40 & 12.90 & 17.10 & 19.70 & 17.10 & 20.80 & 14.90 & 12.10 & 6.50 & 2.20 \\
\hline$W$ & 17.40 & 16.10 & 50.50 & 40.30 & 40.80 & 28.00 & 53.60 & 31.70 & 25.30 & 65.00 & 24.70 & 9.20 \\
\hline$S$ & 61.00 & 85.80 & 80.40 & 205.00 & 285.00 & 282.00 & 108.00 & 252.00 & 145.00 & 83.10 & 71.40 & 42.00 \\
\hline$D S$ & 4.00 & 3.00 & 2.00 & 0.00 & 0.00 & 0.00 & 0.00 & 0.00 & 0.00 & 0.00 & 0.00 & 2.00 \\
\hline$W S$ & 2.36 & 2.84 & 1.99 & 1.79 & 1.68 & 1.50 & 1.57 & 1.54 & 1.56 & 1.92 & 1.72 & 2.87 \\
\hline$\phi_{\mathrm{r}}$ & 86.90 & 96.00 & 94.10 & 96.70 & 90.20 & 93.90 & 94.10 & 94.30 & 94.60 & 93.50 & 95.10 & 95.40 \\
\hline
\end{tabular}

where,

$T \quad$ Ambient air temperature $\left[{ }^{\circ} \mathrm{C}\right]$,

$W \quad$ Average precipitable water $[\mathrm{mm}]$,

$S \quad$ Actual sunshine duration [hour],

DS Depth of the snow cover [cm],

WS Wind speed $\left[\mathrm{m} \cdot \mathrm{s}^{-1}\right]$,

$\phi_{\mathrm{r}} \quad$ Relative humidity [\%].

As shown in Table 3 and Table 4 , the dust fallout in the Helwan region is far beyond the air standard.

\subsection{Prague site details}

The Czech Republic is a hilly country. Sixty-six percent of the total area is at an altitude up to $500 \mathrm{~m}$ above sea level, $33 \%$ of the area lies between 500-1000 $\mathrm{m}$ above sea level, and $1 \%$ lies more than $1000 \mathrm{~m}$ above sea level. The climate is temperate. The annual average air temperature is $6.5-8{ }^{\circ} \mathrm{C}$, and the average annual precipitation amounts to $500-650 \mathrm{~mm}$. Table 5 and Fig. 4 show the annual variation of climatological data and the mean monthly solar radiation in Prague, respectively.

In the framework of former Czechoslovakia the area currently called the Czech Republic was extremely industrial. After the First World War and the formation of the first Czechoslovak Republic, the former industrial regions in central Bohemia, northern Bohemia, and northern Moravia, 


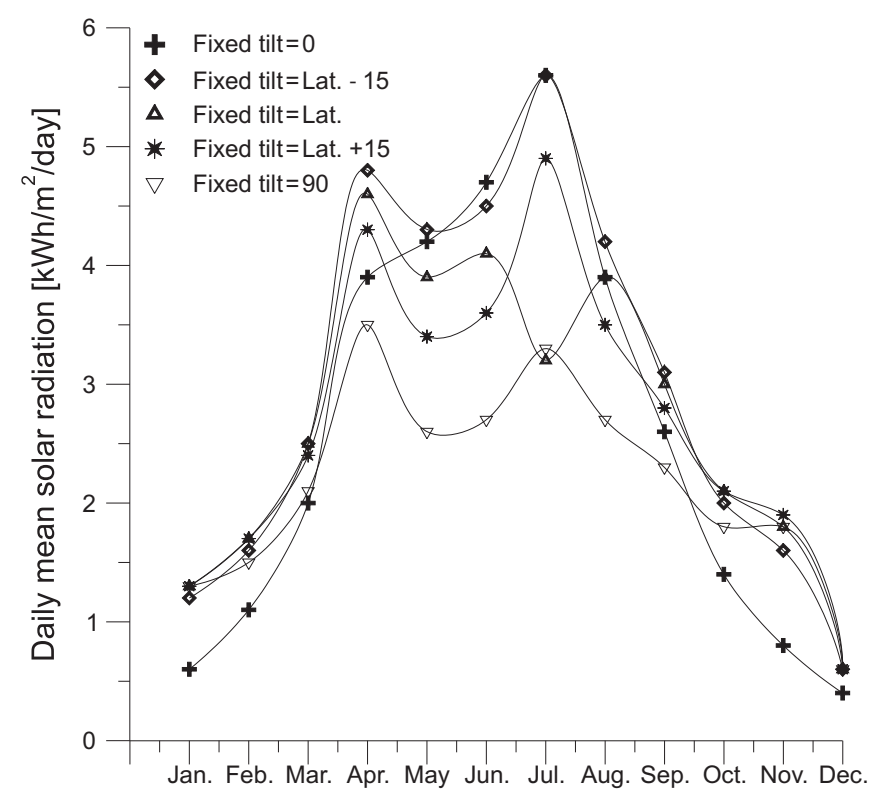

Fig. 4: Annual variation in estimated average daily radiation for a flat plate collector facing south for latitude $50^{\circ}$, and a ground reflectance of 0.2 [17]

etc., were further developed and upgraded. Great structural changes in Czech industry took place after the Second World War, when the Czech lands enormously developed the production of energy, steel, heavy engineering and chemical industries for export to East European countries. Establishing numerous power plants in the lignite basin of northwestern Bohemia satisfied energy demand. It is no wonder that this territory has suffered from excessive levels of major airborne pollutants. The industrial lignite basin in northern Bohemia forms part of the black triangle region, well known in the past as the most polluted area in central Europe. Recently, however, the industrial structure and the activities have changed dramatically. Between 1990 and 2000, the production of energy shifted from the use of fossil to renewable fuels, and demand for coal and petroleum has declined, whereas natural gas and primary electricity have increased to fill the primary energy gap. Consequently, the relative output of the energy industry in producing emissions has fallen. Emissions of solid particles released from industrial combustion of fossil fuels were estimated at 622 and 194 thousand tonnes in the area of the Czech Republic in 1990 and 1995, respectively.

The number of motor vehicles in use has increased dramatically in the Czech Republic in recent years. About 3.5 million vehicles run on the $56000 \mathrm{~km}$ of in roads the country. The most used highway, between Prague and Brno, carries a load of approximately 50000 cars per day. Lead emissions from cars are decreasing, and leaded petrol will no longer be used after 2002. Fig. 5 shows the concentrations of lead in airborne particulate matter on selected sites in Prague between 1983 and 1996. Current Czech Republic lead emissions have been estimated at 125-200 tons per year.

Ninety percent of the sulphur dioxide generated over the period 1980 to 1998 arose from the combustion of fossil fuels in the energy sector. The annual mass emission of sulphur dioxide has fallen over this period, due to the reductions in output from coal and petroleum-fired plants. The decline in sulphur dioxide emissions arising from petroleum is attrib-

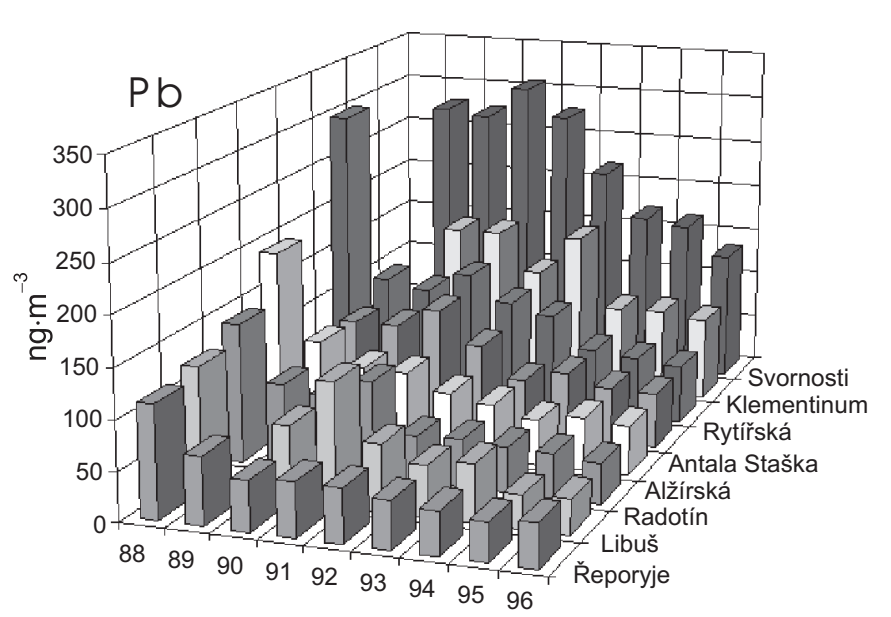

Fig. 5: Lead concentrations in airborne particulate matter at selected sites in Prague [18]

uted to the reduced demand for this product, coupled with the reduced consumption of high sulphurbearing fuel oil by the manufacturing and power generating industries, and the dramatic increase in the demand for the light low sulphur bearing fuels used in the transport sector. The annual $\mathrm{SO}_{2}$ emissions in the Czech Republic declined from 1867 to 598 thousand tonnes, i.e., more than $32 \%$ reduction, which is equivalent to a $1.9 \%$ annual fall.

Yearly average means of dust fallout range from 2 to $5 \mathrm{gm}^{-2} /$ month in southern and southwestern parts of Prague to $10 \mathrm{gm}^{-2} /$ month in the center of the city and industrial zones. Local peak values are probably due to nearby building activities, local sources of pollution, heavy transport and secondary dust pollution. The average dust fallout in 1995 was $6.83 \mathrm{gm}^{-2} /$ month. The level of dust fallout in Prague has been reduced considerably in the last decade, as shown in Fig. 6. Other details concerning potential sources of air pollution and their location in the Czech Republic are mentioned in a Czech moss survey [19].

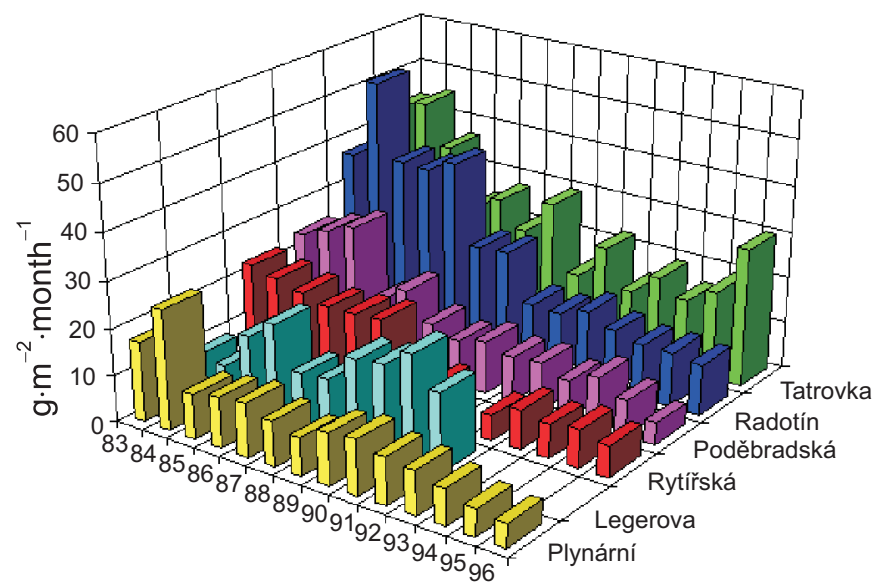

Fig. 6: Dust fallout on selected sites in Prague between 1983 and $1996[19]$ 


\section{Discussion of results}

\subsection{Solar radiation reduction by aerosol in the area of Helwan}

One way of estimating the atmospheric pollution in the town is by comparing values of total solar radiation measured in the town and values measured outside the town during a day or number of days characterized by clear sky. Regarding the global solar radiation data for Helwan and Cairo, it is found that the Helwan annual mean value was $5.48 \mathrm{kWh} / \mathrm{m}^{2} /$ day, which is higher than the Cairo value, which was $5.03 \mathrm{kWh} / \mathrm{m}^{2} /$ day. The total suspended particles (TSP) annual mean value for Helwan was $960 \mu \mathrm{g} / \mathrm{m}^{3}$ as against $583 \mu \mathrm{g} / \mathrm{m}^{3}$ for Cairo. Also, the smoke annual mean value for Helwan was $52 \mu \mathrm{g} / \mathrm{m}^{3}$, while it was $132 \mu \mathrm{g} / \mathrm{m}^{3}$ for Cairo, as shown in Table 6.

Table 6: Annual mean values of G, TSP and Smoke for Cairo and Helwan

\begin{tabular}{|l|c|c|c|}
\hline Region & $\mathbf{G}\left[\mathrm{kWh} / \mathrm{m}^{2} /\right.$ day $]$ & $\mathbf{T S P}\left[\mu \mathrm{g} / \mathrm{m}^{3}\right]$ & Smoke $\left[\mu \mathrm{g} / \mathrm{m}^{3}\right]$ \\
\hline Cairo & 5.03 & 583 & 132 \\
\hline Helwan & 5.48 & 960 & 52 \\
\hline
\end{tabular}

Table 6 shows that the global solar radiation value is higher for Helwan than for Cairo by $8.2 \%$, the TSP value is higher for Helwan than for Cairo by $55 \%$, and the smoke value is higher for Cairo than Helwan by $61 \%$. We found out that the higher level of global solar radiation for Helwan than for Cairo is due to the presence of a higher value of TSP, which contains particles of large size like sand, calcium and iron (see Fig. 7). The presence of these particles tends to make the diffusion of beam solar radiation become diffuse solar radiation, which is added to the global solar radiation value and substitutes the reduction in it due to the reduction in direct solar radiation. In Cairo, by contrast, it is the smoke that makes the absorption greater than the diffusion for beam radiation. This leads to a reduction in the global solar radiation value. The realistic reduction of direct solar radiation due to the presence of large quantities of aerosol particles in the atmospheric mass covering Helwan is about $43 \%$, the reduction of global radiation is $19 \%$, and the increase in diffuse radiation is by $72 \%$.

The clearness index, $K_{\mathrm{I}}$ is another parameter that can describe the situation of atmospheric mass, from the point of view of aerosols. $K_{\mathrm{I}}$ is usually defined as the ratio of the global horizontal irradiation $G$ to the extraterrestrial horizontal irradiance $G_{\mathrm{o}}$. The clearness index is generally less than unity because of extinction by air molecules (Rayleigh scattering) and suspended solid or liquid particles (aerosols) [20]. An alternative presentation is to consider the ratio of the beam normal irradiation, $\mathrm{I}_{\mathrm{bn}}$ to the extraterrestrial normal irradiation, $\mathrm{I}_{\mathrm{on}}$. This ratio should probably be called the "beam transmittance of the atmosphere," and can be correlated

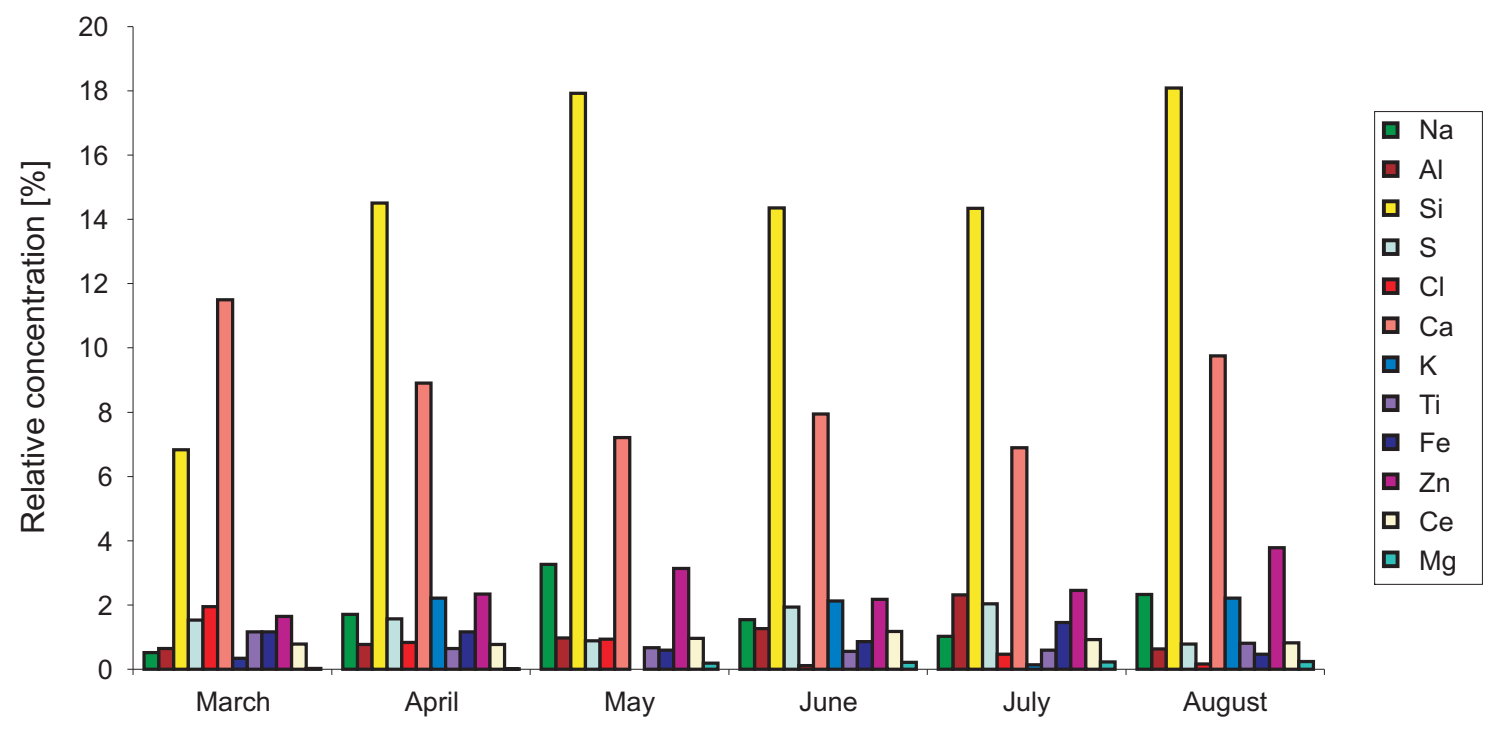

Fig. 7: Results of proton induced X-ray emission analysis of polluting particles at Helwan

Table 7: Monthly mean of extinction coefficient and transmissivity due to aerosols for Helwan

\begin{tabular}{|c|c|c|c|c|c|c|c|c|c|c|c|c|c|}
\hline & & Jan. & Feb. & March & Apr. & May & Jun. & Jul. & Aug. & Sep. & Oct. & Nov. & Dec. \\
\hline \multirow[t]{2}{*}{ B1 } & $\alpha$ & 0.32 & 0.36 & 0.47 & 0.41 & 0.48 & 0.39 & 0.24 & 0.38 & 0.39 & 0.26 & 0.36 & 0.48 \\
\hline & $\tau_{b}$ & 0.55 & 0.55 & 0.46 & 0.58 & 0.48 & 0.59 & 0.71 & 0.57 & 0.58 & 0.64 & 0.55 & 0.40 \\
\hline \multirow[t]{2}{*}{ B2 } & $\alpha$ & 0.41 & 0.42 & 0.59 & 0.54 & 0.73 & 0.56 & 0.49 & 0.48 & 0.49 & 0.41 & 0.49 & 0.50 \\
\hline & $\tau_{b}$ & 0.43 & 0.52 & 0.38 & 0.48 & 0.42 & 0.47 & 0.52 & 0.50 & 0.51 & 0.49 & 0.41 & 0.35 \\
\hline \multirow[t]{2}{*}{ B3 } & $\alpha$ & 0.36 & 0.41 & 0.47 & 0.41 & 0.59 & 0.45 & 0.38 & 0.39 & 0.35 & 0.41 & 0.42 & 0.45 \\
\hline & $\tau_{b}$ & 0.49 & 0.51 & 0.49 & 0.58 & 0.51 & 0.54 & 0.61 & 0.56 & 0.61 & 0.52 & 0.46 & 0.39 \\
\hline \multirow[t]{2}{*}{ B4 } & $\alpha$ & 0.21 & 0.25 & 0.36 & 0.31 & 0.45 & 0.31 & 0.24 & 0.24 & 0.26 & 0.23 & 0.27 & 0.33 \\
\hline & $\tau_{\mathrm{b}}$ & 0.64 & 0.65 & 0.56 & 0.66 & 0.59 & 0.65 & 0.72 & 0.70 & 0.69 & 0.67 & 0.59 & 0.49 \\
\hline
\end{tabular}


against the clearness index. Correlations of this form have a special intuitive appeal, since one expects the beam transmittance to increase monotonically with the clearness index. A pioneering effort with this format is the work of Boes E. C., et al., [21]. However, the variations of this factor with wavelength are generally unknown, especially in tropical conditions. The beam transmittance may be expected to follow a Bougurer's Law dependence on atmospheric extinction and air mass, such that:

$$
\tau_{\mathrm{b}}=\exp (-\alpha \cdot m) \text {. }
$$

Table 7 shows the annual variation of the mean monthly values of the atmospheric transparency factor $\exp (-\alpha \cdot m)$, for selected interval bands $(\mathrm{B} 1=0.290-0.530 \mu \mathrm{m}$, $\mathrm{B} 2=0.530-0.630 \mu \mathrm{m}, \mathrm{B} 3=0.630-0.695 \mu \mathrm{m}$, and $\mathrm{B} 4=0.695-2.800 \mu \mathrm{m})[22]$.

\subsection{Determination of different atmospheric turbidity parameters}

Stagnating air led to a polluted atmosphere over Helwan during the measurement period. The early morning and late afternoon observations correspond to periods for which there were smaller temperature and relative humidity variations. Thus, air temperature varied slightly from 19 to $21^{\circ} \mathrm{C}$ while humidity remained almost constant at $62-58 \%$, within the same period. After this time interval, air temperature increased steadily to reach $28^{\circ} \mathrm{C}$ by midday while the relative humidity fell steadily to about $40 \%$. Light winds of $1.3-2 \mathrm{~ms}^{-1}$ were blowing in the early morning, strengthening later to about $3-3.5 \mathrm{~ms}^{-1}$. Such patterns were observed over the whole measurement period.

Atmospheric turbidity coefficients were obtained from pyrheliometric measurements of direct solar radiation. The monthly variation of the atmospheric turbidity coefficients was calculated from their respective monthly values and listed in Appendix (A and B). The seasonal (summer and winter) and annual average values of $T_{\mathrm{L}}$ and $\beta$ were also computed from Appendix (A), and presented in Appendix (C). All of them show similar evolutions, with the higher values in

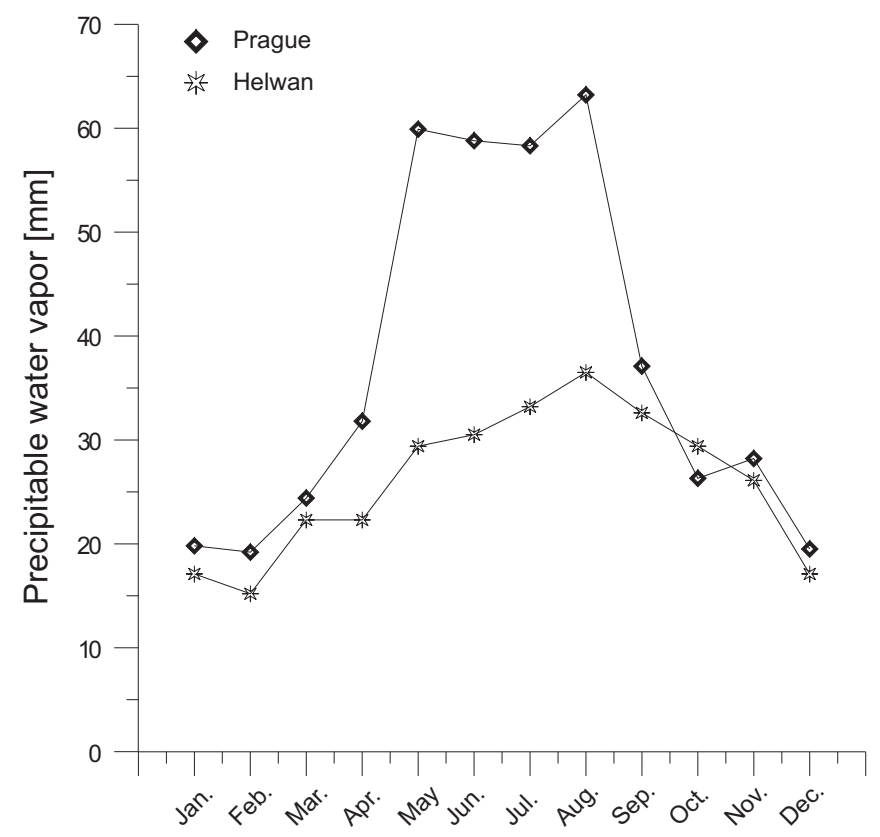

Fig. 8: Precipitable water vapour for the Helwan and Prague sites summer and lower values in winter. We note that autumn and spring values are rather high and closer to summer values than to winter values. The higher values in summer are due to higher average precipitable water during the same months (see Fig. 8). The atmospheric humidity strongly influences the large scatter shown in this diagram, an aspect that can be explained in the following manner. Consider an instant when the relative humidity and atmospheric turbidity are both high. As the solar altitude increases, the increasing sunshine will evaporate the liquid particles of the aerosols, which will decrease the turbidity and increase the precipitable water. Now consider an instant when the relative humidity and the atmospheric turbidity are both low. As the solar altitude increases, the increased sunshine evaporates water from the soil and the river, thereby increasing the precipitable water, and forms liquid particles in the atmosphere, which contribute to increased turbidity.

\subsection{Relationship between linke factor and ngström coefficient}

The plot of the 108 computed values of $\beta$ versus $T_{L}$ for both sites, Fig. 9, shows a linear relationship. Using a linear regression technique the following model has been found from the measured data with a correlation coefficient equal to 0.84 and 0.71 respectively:

$$
\begin{array}{ll}
\beta=-0.194933+0.0620059 T_{\mathrm{L}} & \text { Helwan } \\
\beta=-0.162108+0.0449825 T_{\mathrm{L}} & \text { Prague }
\end{array}
$$

The relation of Equation (9) is similar to the model reported for Avignon, France:

$$
\beta=-0.103+0.052 T_{\mathrm{L}} \text {. }
$$

and to the relationship of Hinzpeter for Potsdam, Germany [23]:

$$
\beta=-0.100+0.050 T_{\mathrm{L}} .
$$

Equations (9-11) indicate that the linear regression model fitted to $\beta$ versus $T_{\mathrm{L}}$ for Helwan, desert climate, is similar to the models reported for Prague, Czech Republic, Avignon, France and Potsdam, Germany, temperate climate. The coef-

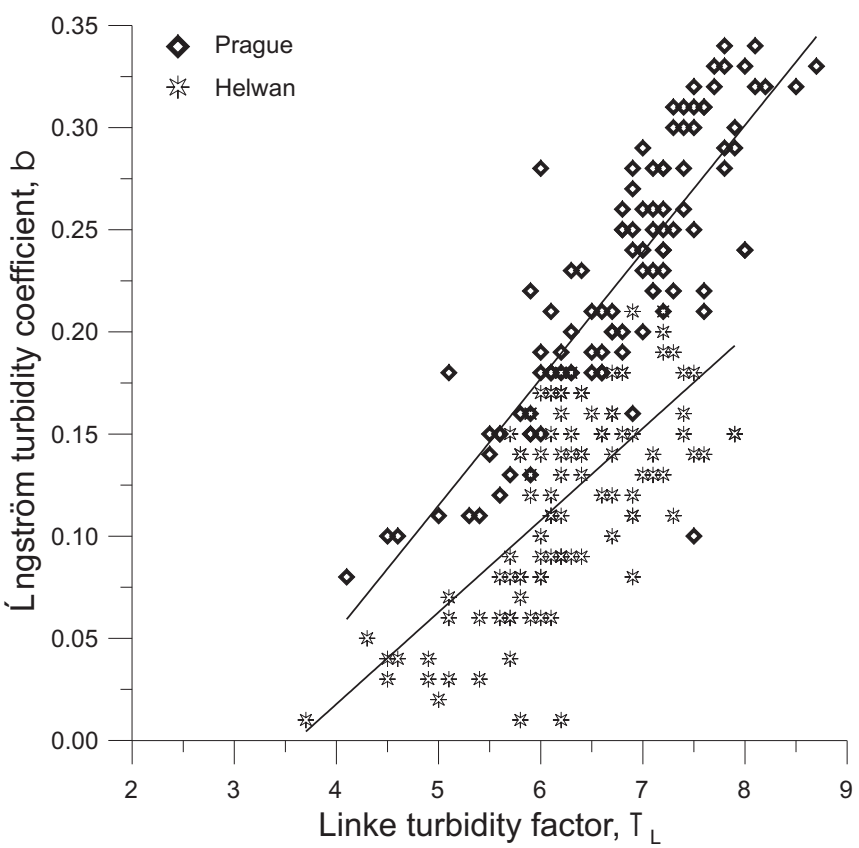

Fig. 9: Plot of $\beta$ versus $T_{\mathrm{L}}$ for both sites 
ficients of the Helwan model are different from the approximately equal coefficients of the Prague, Avignon and Potsdam models.

\section{Conclusions}

The results obtained with a proton induced X-ray emission analytical procedure and statistical evaluations of the data sets collected and presented above provide new information on the aerosol load of the Egyptian and Czech atmosphere. The nature of the contributing sources has been investigated and some attempts have been made to indicate the role played by neighboring regions in determining the air quality at the sites mentioned. The study of an experimental set of direct spectral irradiances measured during the test period enables the retrieval of spectral aerosol optical depth and its use as a turbidity index at selected wavelengths. The difficulties in making a direct comparison of our data with other data sets at other measured sites are mainly due to use of different instruments and techniques. However, the obtained values of these turbidity parameters serve as reference data to estimate the climatological behavior of atmospheric aerosols in these areas of study.

The variation in the monthly average values of $\beta$ and $T_{\mathrm{L}}$ at Helwan shows a similar trend to that of Prague. However, Helwan shows higher values of atmospheric turbidity coefficients than Prague, due to the influence of the desert climate.

\section{References}

[1] Linke, L.: Transmission Koeffizient und Trübungsfaktor Beitr. Atmos., 1922, Vol. 10, pp. 91

[2] ngström, A.: Techniques of determining the turbidity of the atmosphere. Tellus, 1961, Vol. 13, pp. 214

[3] Mosalam, M. A.: Solar radiation and air pollution in Cairo. Proceedings of the $3^{\text {rd }}$ Arab international solar energy conference, Baghdad, Iraq, 1988, pp. 53

[4] Mosalam Shaltout, M. A., Ghoniem, M. M., Hassan, A. H.: Measurements of the air pollution effects on the color portions of solar radiation at Helwan, Egypt. Renewable Energy, Vol. 9, No. 1-4/1996, pp. 1279

[5] Mosalam Shaltout, M. M., Hassan, A. H., Rahoma, U. A.: Measurements of suspended particles and aerosols in atmosphere of Helwan, Egypt. Proceeding of $6^{\text {th }}$ international conference on energy and environment, Cairo, Egypt, 1998, Vol. 2, pp. 567

[6] Rizk, H. F., Farag, S. A., Ateia, A. A.: Effect of pollutants on spectral atmospheric transmissivity in Cairo. Environment Int., 1986, Vol. 11, pp. 243

[7] Fathy, A. M.: Ultraviolet solar radiation at Helwan and its dependence on atmospheric conditions. M. Sc. thesis, Faculty of Science, Helwan University, 1992, Ch. 5

[8] Rahoma, U. A.: Atmospheric transparency at Helwan from solar radiation measurements and its correlation with air pollution. M. Sc. thesis, Faculty of science, Helwan University, 1992, pp. 101

[9] Hedin, L., Granat, L., Likens, E., Buishand, A.: Steep declines in atmospheric base cations in regions of both Europe and North America. Nature, 1994, Vol. 36, pp. 351
[10] Heintzenberg, J., Müller, K., Birmili, W., Spindler, G., Widensohler, A.: Mass related aerosol properties over the Leipzig basin. J. Geophys. Res., 1998, Vol. 103, pp. 13125

[11] Draxler, R.: Estimating vertical diffusion from routine meteorological measurements. Atmospheric Environment, 1979, Vol. 13, pp. 1559

[12] Phan, C. N.: Procedures for quality control and analysis of data from a solar meteorological monitoring station. M.Sc. thesis, School of Mechanical Engineering, Georgia Institute of Technology, 1980

[13] Kasten, F.: A simple parameterization of the pyrheliometric formula for determining the Linke turbidity factor. Meteor. Rdsch. 33, 1980, pp. 124-127

[14] Louche, A., Peri, G., Iqbal, M.: An analysis of Linke turbidity factor. Solar Energy, Vol. 37, No. 6/1986, pp. 393

[15] Frohlich, C.: Extraterrestrial solar radiation, Course on physical climatology for solar and wind energy. International Center for Theoretical Physics, Trieste, Italy, 1986

[16] Iqbal, M.: An introduction to solar radiation. Academic Press, New York, 1983

[17] Hamdy K. Elminir, Rabab, H. A., Fathy, A. M., Benda, V.: Solar radiation on tilted south oriented surfaces - I: Validation of transfer model. $6^{\text {th }}$ International Conference of Solar Energy Stored and Applied Photochemistry, Solar'01, Cairo, Egypt, 2001

[18] Svoboda, K., Čermák, J., Hrtman, M.: Source of heavy metal emissions in the Czech Republic and Ways of decreasing emissions - emissions from combustion of coal and wastes, Part I. Ochrana ovzduší, Vol. 10, No. 4/1998, pp. 6

[19] Sucharová, J., Suchara, I.: Results of the international biomonitoring program 1995. Research Institute of Ornamental Gardening (VUOZ), Průhonice, 1998, pp. 183

[20] Casiniere, A. L., Grenier, J. C., Cabot, T., Werneck-Faga, M.: Altitude effect on the clearness index in the French Alps. Solar Energy, 1993, Vol. 51, pp. 93

[21] Boes, E. C., Anderson, H. E., Hall, I. J., Prairie, R. R., Stromberg, R. T.: Availability of direct, total and diffuse solar radiation to fixed and tracking collectors in the U.S.A. Report No. SAND 77-0885, Sandia National Laboratories, 1977

[22] Mosalam Shaltout, M. M., Tadros, M. T., El-Metwally, M.: Studying the extinction coefficient due to aerosol particles at different spectral bands in some regions at great Cairo. Renewable Energy, 2000, Vol. 19, pp. 597

[23] Katz, M., Baille, A., Mermier, M.: Atmospheric turbidity in a semi-rural site - I: Evaluation and comparison of different atmospheric turbidity coefficients. Solar energy, Vol. 28, No. 4/1982, pp. 323

Eng. Hamdy Kamal Elminir

phone: +420224352212

fax: +420224353949

e-mail: ehamdy@hotmail.com

Doc. Ing. Vítězslav Benda, CSc. e-mail: benda@feld.cvut.cz

Department of Electrotechnology

Czech Technical University in Prague

Faculty of Electrical Engineering

Technická 2, 16627 Praha 6, Czech Republic 


\section{Appendix (A)}

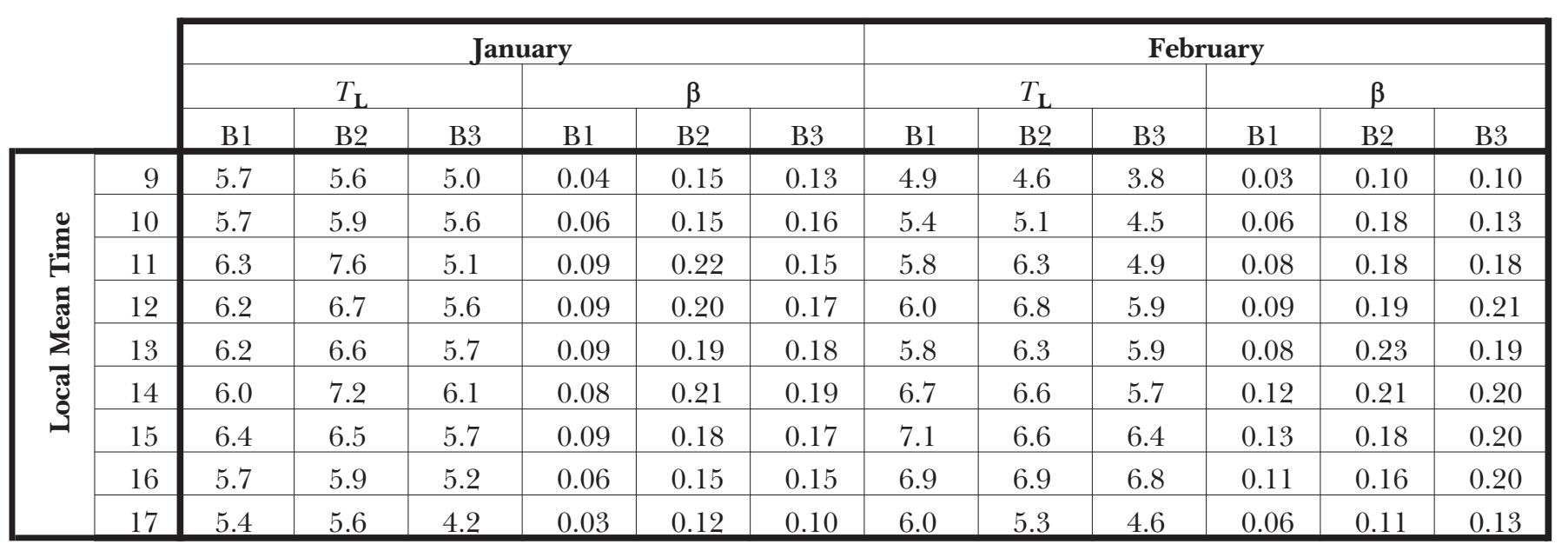

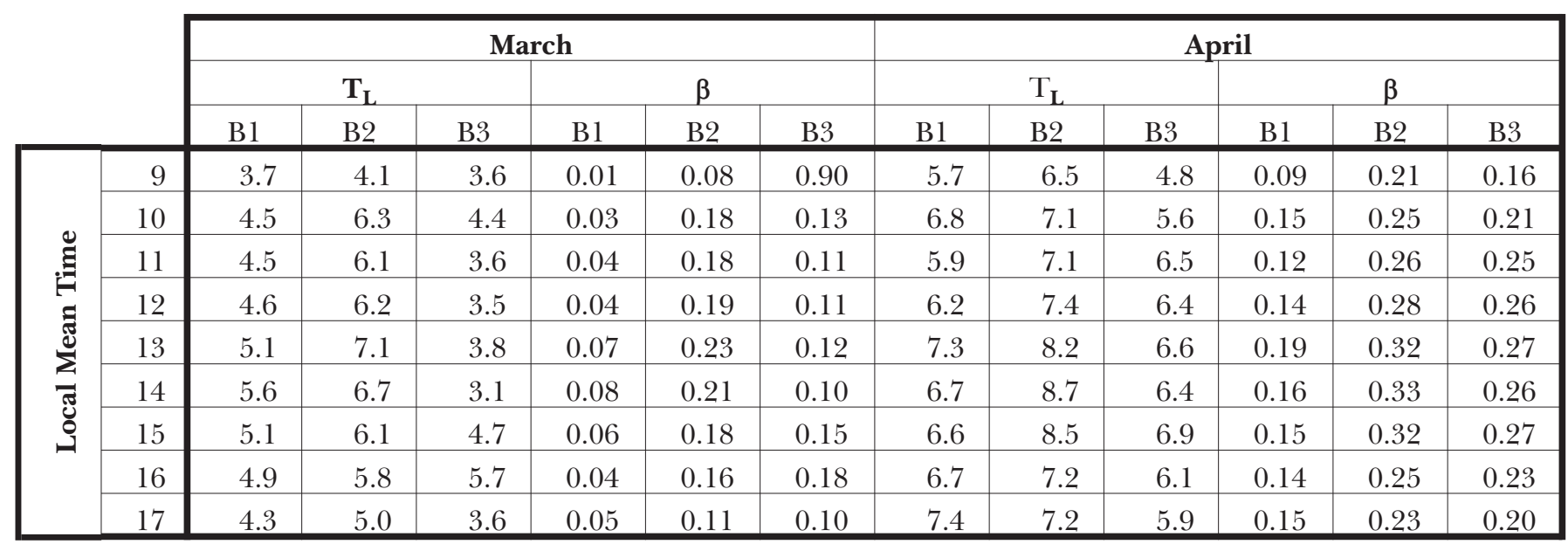

\begin{tabular}{|c|c|c|c|c|c|c|c|c|c|c|c|c|c|}
\hline & & \multicolumn{6}{|c|}{ May } & \multicolumn{6}{|c|}{ June } \\
\hline & & \multicolumn{3}{|c|}{$T_{\mathbf{L}}$} & \multicolumn{3}{|c|}{$\beta$} & \multicolumn{3}{|c|}{$T_{\mathbf{L}}$} & \multicolumn{3}{|c|}{$\beta$} \\
\hline & & B1 & B2 & B3 & $\mathrm{B} 1$ & $\mathrm{~B} 2$ & B3 & B1 & B2 & B3 & $\mathrm{B} 1$ & $\mathrm{~B} 2$ & B3 \\
\hline \multirow{9}{*}{ 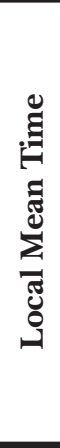 } & 9 & 6.4 & 7.0 & 5.8 & 0.13 & 0.24 & 0.21 & 5.9 & 6.8 & 4.8 & 0.13 & 0.25 & 0.19 \\
\hline & 10 & 6.3 & 6.8 & 5.8 & 0.15 & 0.25 & 0.23 & 5.8 & 6.9 & 5.1 & 0.14 & 0.27 & 0.22 \\
\hline & 11 & 7.2 & 7.2 & 5.8 & 0.20 & 0.28 & 0.24 & 5.9 & 7.5 & 5.0 & 0.16 & 0.31 & 0.22 \\
\hline & 12 & 7.2 & 7.4 & 5.9 & 0.21 & 0.30 & 0.25 & 6.9 & 7.7 & 5.2 & 0.21 & 0.33 & 0.24 \\
\hline & 13 & 6.2 & 7.3 & 6.4 & 0.16 & 0.30 & 0.28 & 6.2 & 7.5 & 4.5 & 0.18 & 0.32 & 0.21 \\
\hline & 14 & 6.7 & 7.6 & 6.3 & 0.18 & 0.31 & 0.27 & 6.2 & 8.1 & 5.9 & 0.18 & 0.34 & 0.27 \\
\hline & 15 & 6.8 & 7.5 & 6.2 & 0.18 & 0.30 & 0.26 & 6.2 & 8.0 & 5.9 & 0.17 & 0.33 & 0.26 \\
\hline & 16 & 7.2 & 7.9 & 6.2 & 0.19 & 0.30 & 0.24 & 6.8 & 8.1 & 5.9 & 0.18 & 0.32 & 0.25 \\
\hline & 17 & 7.5 & 7.8 & 6.1 & 0.18 & 0.28 & 0.23 & 6.7 & 7.8 & 6.0 & 0.16 & 0.29 & 0.23 \\
\hline
\end{tabular}




\section{Appendix (A) - continued}

\begin{tabular}{|c|c|c|c|c|c|c|c|c|c|c|c|c|c|}
\hline & & \multicolumn{6}{|c|}{ July } & \multicolumn{6}{|c|}{ August } \\
\hline & & \multicolumn{3}{|c|}{$T_{\mathbf{L}}$} & \multicolumn{3}{|c|}{$\beta$} & \multicolumn{3}{|c|}{$T_{\mathbf{L}}$} & \multicolumn{3}{|c|}{$\beta$} \\
\hline & & B1 & B2 & B3 & B1 & B2 & B3 & B1 & B2 & B3 & B1 & B2 & B3 \\
\hline \multirow{9}{*}{ 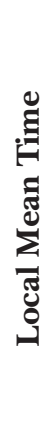 } & 9 & 5.7 & 6.4 & 4.5 & 0.15 & 0.23 & 0.18 & 6.1 & 6.1 & 4.6 & 0.12 & 0.21 & 0.17 \\
\hline & 10 & 5.8 & 7.1 & 5.3 & 0.14 & 0.28 & 0.23 & 6.0 & 5.9 & 4.4 & 0.14 & 0.22 & 0.18 \\
\hline & 11 & 6.1 & 7.6 & 4.8 & 0.17 & 0.31 & 0.22 & 6.4 & 6.9 & 5.2 & 0.17 & 0.28 & 0.23 \\
\hline & 12 & 6.3 & 7.3 & 5.2 & 0.18 & 0.31 & 0.24 & 6.3 & 6.0 & 5.1 & 0.18 & 0.28 & 0.23 \\
\hline & 13 & 6.0 & 7.8 & 5.6 & 0.17 & 0.34 & 0.26 & 6.2 & 7.0 & 5.4 & 0.17 & 0.29 & 0.24 \\
\hline & 14 & 6.1 & 7.8 & 5.5 & 0.17 & 0.33 & 0.26 & 6.2 & 7.4 & 5.6 & 0.17 & 0.31 & 0.25 \\
\hline & 15 & 5.9 & 7.7 & 5.7 & 0.16 & 0.32 & 0.25 & 6.4 & 7.5 & 5.7 & 0.17 & 0.03 & 0.25 \\
\hline & 16 & 6.1 & 7.2 & 5.2 & 0.15 & 0.28 & 0.22 & 6.5 & 6.8 & 5.8 & 0.16 & 0.26 & 0.24 \\
\hline & 17 & 6.3 & 7.9 & 4.2 & 0.14 & 0.29 & 0.17 & 7.4 & 7.0 & 5.7 & 0.18 & 0.24 & 0.22 \\
\hline
\end{tabular}

\begin{tabular}{|c|c|c|c|c|c|c|c|c|c|c|c|c|c|}
\hline & & \multicolumn{6}{|c|}{ September } & \multicolumn{6}{|c|}{ October } \\
\hline & & \multicolumn{3}{|c|}{$T_{\mathbf{L}}$} & \multicolumn{3}{|c|}{$\beta$} & \multicolumn{3}{|c|}{$T_{\mathbf{L}}$} & \multicolumn{3}{|c|}{$\beta$} \\
\hline & & $\mathrm{B} 1$ & B2 & B3 & $\mathrm{B} 1$ & $\mathrm{~B} 2$ & B3 & B1 & B2 & B3 & $\mathrm{B} 1$ & $\mathrm{~B} 2$ & B3 \\
\hline \multirow{9}{*}{ 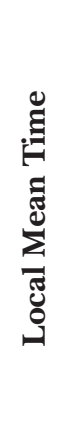 } & 9 & 6.2 & 6.1 & 4.8 & 0.01 & 0.18 & 0.16 & 5.8 & 5.5 & 4.3 & 0.07 & 0.14 & 0.12 \\
\hline & 10 & 5.8 & 6.0 & 5.0 & 0.01 & 0.19 & 0.18 & 5.7 & 6.0 & 5.4 & 0.08 & 0.18 & 0.17 \\
\hline & 11 & 6.4 & 6.9 & 4.3 & 0.14 & 0.24 & 0.15 & 6.1 & 6.3 & 5.6 & 0.11 & 0.20 & 0.19 \\
\hline & 12 & 6.2 & 6.9 & 5.5 & 0.13 & 0.25 & 0.21 & 6.2 & 7.5 & 6.0 & 0.11 & 0.25 & 0.21 \\
\hline & 13 & 6.4 & 7.0 & 5.8 & 0.14 & 0.26 & 0.22 & 6.1 & 7.2 & 4.9 & 0.11 & 0.24 & 0.17 \\
\hline & 14 & 6.6 & .2 & 6.2 & 0.15 & 0.26 & 0.24 & 6.1 & 7.0 & 5.5 & 0.11 & 0.23 & 0.19 \\
\hline & 15 & 6.9 & 7.4 & 6.4 & 0.15 & 0.26 & 0.24 & 6.6 & 7.2 & 5.2 & 0.12 & 0.24 & 0.17 \\
\hline & 16 & 7.4 & 7.3 & 8.2 & 0.16 & 0.25 & 0.31 & 7.0 & 7.1 & 6.0 & 0.13 & 0.22 & 0.20 \\
\hline & 17 & 7.1 & 7.1 & 8.7 & 0.14 & 0.22 & 0.30 & 6.0 & 6.6 & 5.4 & 0.10 & 0.18 & 0.16 \\
\hline
\end{tabular}

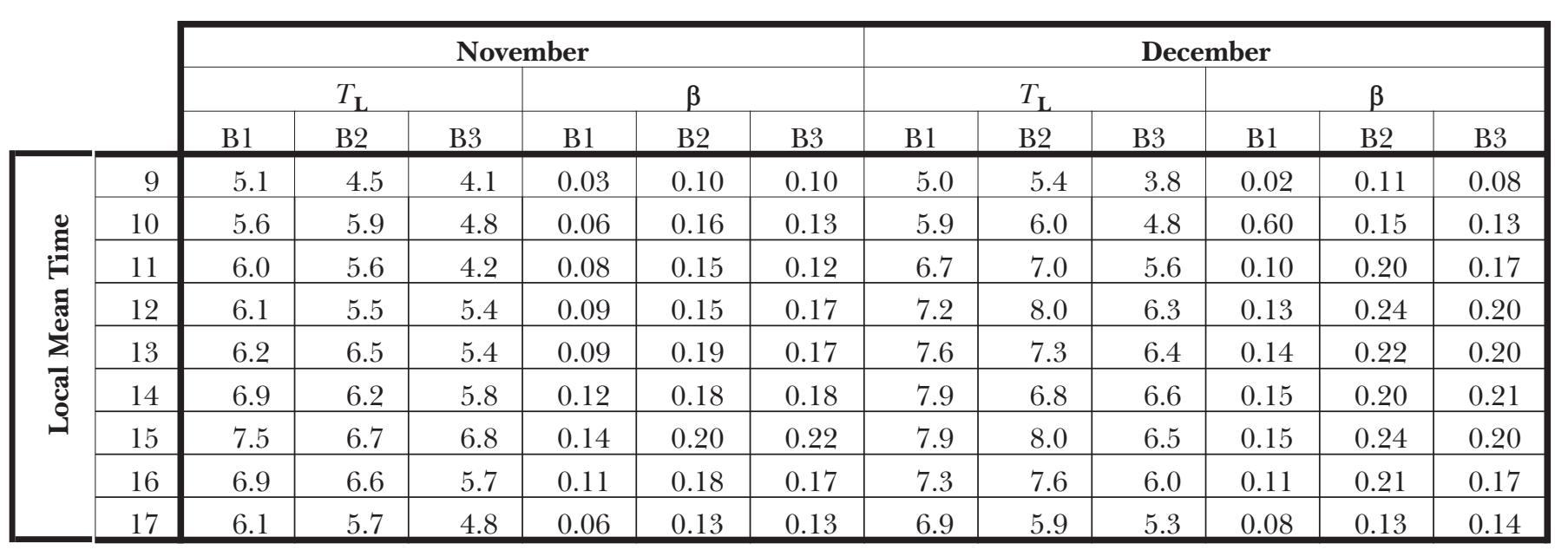

Monthly mean variations of Linke turbidity factor, $T_{\mathbf{L}}$ and ngström turbidity coefficient, $\beta$ for different bands in visible range at Helwan 


\section{Appendix (B)}

\begin{tabular}{|l|l|l|l|l|l|l|l|l|l|l|l|l|}
\hline & Jan. & Feb. & Mar. & Apr. & May & Jun. & Jul. & Aug. & Sept. & Oct. & Nov. & Dec. \\
\hline$T_{\mathrm{L}}$ & 2.75 & 3.52 & 3.34 & 4.29 & 4.75 & 5.42 & 4.83 & 5.21 & 4.33 & 5.17 & 3.94 & 3.13 \\
\hline$\beta$ & 0.062 & 0.073 & 0.091 & 0.122 & 0.152 & 0.190 & 0.158 & 0.168 & 0.131 & 0.168 & 0.128 & 0.087 \\
\hline
\end{tabular}

Atmospheric turbidity parameters in visible band at Prague, Czech Republic

\section{Appendix (C)}

\begin{tabular}{|c|c|c|c|c|c|c|c|c|c|c|c|}
\hline \multicolumn{6}{|c|}{ Summer (April - September) } & \multicolumn{6}{|c|}{ Winter (October - March) } \\
\hline \multicolumn{3}{|c|}{$T_{\mathrm{L}}$} & \multicolumn{3}{|c|}{$\beta$} & \multicolumn{3}{|c|}{$T_{\mathrm{L}}$} & \multicolumn{3}{|c|}{$\beta$} \\
\hline B1 & $\mathrm{B} 2$ & B3 & $\mathrm{B} 1$ & $\mathrm{~B} 2$ & B3 & B1 & $\mathrm{B} 2$ & B3 & $\mathrm{B} 1$ & $\mathrm{~B} 2$ & B3 \\
\hline \multirow[t]{5}{*}{6.45} & 7.26 & 5.87 & 0.15 & 0.27 & 0.23 & 6.02 & 6.32 & 5.17 & 0.09 & 0.18 & 0.17 \\
\hline & & & \multicolumn{6}{|c|}{ Annual Mean Value } & & & \\
\hline & & & \multicolumn{3}{|c|}{$T_{\mathrm{L}}$} & \multicolumn{3}{|c|}{$\beta$} & & & \\
\hline & & & $\mathrm{B} 1$ & $\mathrm{~B} 2$ & B3 & $\mathrm{B} 1$ & $\mathrm{~B} 2$ & B3 & & & \\
\hline & & & 6.23 & 6.79 & 5.42 & 0.12 & 0.23 & 0.20 & & & \\
\hline
\end{tabular}

Seasonal (summer and winter) and annual average values of $T_{\mathbf{L}}$ and $\boldsymbol{\beta}$ for Helwan site 